\title{
PADRONIZAÇÃO DE MEDIDAS DE CRESCIMENTO E PRODUÇÃO EM EXPERIMENTOS COM PUPUNHEIRA PARA PALMITO $^{1}$
}

\author{
Charles R. CLEMENT ${ }^{2}$, Marilene Leão Alves BOVI ${ }^{3}$
}

\begin{abstract}
RESUMO - Pesquisas com a pupunheira (Bactris gasipaes Kunth) têm sido intensificadas em vários paises devido ao crescente uso dessa espécie para produção agrícola de palmito, em substituição à exploração predatória de palmeiras silvestres. Por ser uma espécie ainda pouco estudada, pesquisadores utilizam diferentes caracteres para avaliar o crescimento e a produção, freqüentemente medidos de formas distintas, impossibilitando assim a comparação de resultados. O presente trabalho faz uma revisão dos métodos para análise de crescimento e produção em pupunheira, e propõe a padronização de medidas a serem usadas em experimentos agronômicos e genéticos visando a produção de palmito. As medidas vegetativas essenciais são altura, número de folhas e número de perfilhos, enquanto as opcionais são diâmetro da planta, área foliar e biomassa foliar. As medidas produtivas essenciais são número de palmitos colhidos, peso e comprimento do palmito (tipo exportação), considerando-se como opcionais peso do estipe tenro (resíduo basal), peso da folha tenra (resíduo apical) e diâmetro do palmito. $\mathrm{O}$ uso dessas medidas, como explicadas aqui, permitirá a comparação de resultados entre experimentos em diferentes ambientes e com diferentes genótipos, bem como a estimação de vários parâmetros físiológicos de crescimento e produção.
\end{abstract}

Palavras-chave: Bactris gasipaes, análise de crescimento, medidas lineares, medidas numéricas, correlações com produção

\section{Standardization of Growth and Yield Measurements in Pejibaye Heart-of-palm Experiments}

ABSTRACT - Research with pejibaye or peach palm (Bactris gasipaes Kunth) has intensified in various countries due to its increasing use in plantations for heart-of-palm production, as a substitute for the predatory extraction of wild palms. Because the species is still understudied, researchers use different traits to evaluate its growth and yield, frequently measured in different ways, making direct comparisons of experiments impossible. This paper reviews methods used to analyse growth and yield in pejibaye and proposes a set of standard measurements to be used to evaluate agronomic and genetic experiments for heart-of-palm production. The essential vegetative measurements are plant height, leaf number and offshoot number, and the optional measurements are plant diameter, individual and whole plant leaf area and biomass. The essential yield measurements are number of harvested hearts-of-palm ("palmitos") and heart-of-palm weight and length (export type only), and the optional measurements are tender stem (basal by-product) weight, tender leaf (apical by-product) weight and heart-of-palm diameter. The use of these measurements, as explained here, will permit comparison of experiments in different environments and with different genotypes, as well as the estimation of useful growth, yield and physiological parameters.

Key-words: Bactris gasipaes, growth analysis, linear measurements, numeric measurements, yield correlations

'Uma versão preliminar deste trabalho foi apresentada durante o $38^{\circ}$ Congresso Brasileiro de Olericultura, Petrolina, PE, 29 julho 1998.

${ }^{2}$ Instituto Nacional de Pesquisas da Amazônia, Cx. Postal 478, 69011-970 Manaus, AM, Brasil. e-mail: cclement@inpa.gov.br

${ }^{3}$ Instituto Agronônico de Campinas, Cx. Postal 28, 13001-970 Campinas, SP, Brasil. e-mail: mlabovi@cec.iac.br 


\section{INTRODUÇÃO}

As pesquisas com a pupunheira (Bactris gasipaes Kunth, Palmae) visando a produção de palmito tiveram início na Costa Rica durante a década de 1960 (Camacho \& Soria, 1970), na época em que a extração predatória já havia inviabilizado a colheita econômica de palmito das populações silvestres de Euterpe precatoria (Mart.). Ao longo da década de 1970, os plantios costarriquenhos expandiram lentamente e ensaios foram instalados em numerosas áreas de América tropical. As pesquisas no Brasil com a pupunha para esta finalidade se iniciaram no começo da década de 1970 no Instituto Agronômico de Campinas (Germek, 1978) e no final dessa mesma década no Instituto Nacional de Pesquisas da Amazônia (Moreira Gomes \& Arkcoll, 1988). No início da década de 1990 , o plantio de pupunheira para palmito no Brasil teve grande expansão e o número de grupos trabalhando com a espécie cresceu rapidamente. Infelizmente, a integração entre estes grupos, tanto novos como velhos, não era muito boa, e cada grupo desenvolveu sua própria metodologia, as vezes baseada em trabalhos com outras palmeiras, as vezes em trabalhos com dicotiledoneas. O resultado foi uma diversidade de metodologias que dificulta a comparação de resultados. Este trabalho revisará as metodologias mais importantes e sugerirá uma metodologia padrão para futuros experimentos com a pupunheira.
A experimentação com palmeiras visando a produção de palmito é diferente àquela destinada a frutos. Devido a colheita periódica e constante, as plantas apresentam-se em permanente estádio vegetativo (Clement, 1995), e a velocidade com que a fitomassa cresce após cada colheita torna-se um indicador da produtividade e da vida econômica do cultivo. Variáveis relacionadas ao crescimento e a precocidade da planta são fundamentais, visto que o produto, palmito, nada mais é do que um conjunto de folhas imaturas, envoltas pelas bainhas das folhas mais velhas (Ferreira et al., 1976).

\section{Correlações}

positivas significativas foram encontradas entre caracteres vegetativos, tais como diâmetro, altura e número de folhas, e componentes diretos da produção (massa, diâmetro e comprimento do palmito) (Bovi et al., 1988; 1992; 1993a; Clement et al., 1988; Moreira Gomes \& Arkcoll, 1988). Por outro lado, foi verificado que essas correlações são válidas desde o início do cultivo, indicando a possibilidade de seleção precoce de plantas superiores para palmito usando esses mesmos caracteres (Bovi et al., 1993b; Clement, 1995). Ganhos genéticos esperados por ciclo, quando da seleção precoce, são significativos e devem ser explorados (Bovi et al, , 1993b). Devido à pupunheira para palmito ser cultivada em alta densidade (mínimo de 5.000 plantas por hectare), a competição interplantas (infraespecífica) afeta não só a 
produção, mas também a própria fisiologia da planta.

Considerando esses fatores, conclui-se que a análise de crescimento em pupunheira é altamente recomendada, tanto para experimentos agronômicos, como para critério de seleção, e de fato a maioria dos experimentos realizados até o momento faz uso de algum tipo de análise de crescimento. No entanto, pesquisadores vêm utilizando diferentes caracteres, freqüentemente medidos de formas distintas, para avaliar o crescimento e a produção, dificultando a comparação direta de resultados. Os objetivos deste trabalho são revisar as metodologias usadas em experimentos agronômicos e genéticos até o presente e propor a padronização de medidas a serem utilizadas em experimentos para a produção de palmito de pupunheira no futuro.

\section{ANÁLISE DE CRESCIMENTO}

A análise de crescimento permite conhecer diferenças funcionais e estruturais entre plantas, de forma a identificar respostas à aplicação de diferentes tratamentos e/ou selecionar genótipos mais eficientes (Radford, 1967; Evans, 1972; Causton \& Venus, 1981). O crescimento é avaliado através de variações em magnitude de alguma característica ou estrutura morfológica da planta ao longo do tempo. Por sua vez, essas variações temporais permitem acompanhamento da produção fotossintética efetiva. Isso porque mais de $95 \%$ da matéria seca acumulada pelas plantas ao longo de seu crescimento provém da atividade fotossintética (Causton \& Venus, 1981). Menos de $5 \%$ da matéria seca advém da absorção de nutrientes do solo, embora a inter-relação entre fotossintese e absorção seja fundamental ao processo como um todo. A produção fotossintética efetiva, geralmente expressa em termos de aumento de biomassa ao longo do tempo, é resultante do balanço entre fotossintese bruta, respiração, fotorrespiração e perdas devidas à senescência de tecidos e órgãos.

$\mathrm{O}$ crescimento da planta pode ser avaliado por meio de medidas de diferentes tipos, sendo as mais comuns: numéricas, lineares, superficiais e massa. O uso de uma e/ ou de outra depende principalmente dos objetivos do pesquisador, bem como da disponibilidade de material, mão-de-obra, tempo e equipamentos necessários para a realização das medidas.

\section{Medidas numéricas (número} de unidades estruturais): número de folhas e de perfilhos. O número de folhas vivas, verdes ou funcionais está diretamente relacionado com o número de folhas internas e, portanto, com a produção de palmito (Bovi et al., 1988; 1992; Clement et al., 1988). $\mathrm{O}$ número de folhas reflete bem o efeito de estresse hídrico e adubação (Bovi, 1998; Bovi et al., 1988, 1998; Ramos et al., 1999). O número de perfilhos por planta ao longo do ciclo da cultura é fundamental, pois avalia a capacidade de regeneraçào da planta, 
sendo ainda muito afetado pela densidade do plantio (Moreira Gomes et al., 1988).

Medidas lineares: altura e diâmetro da haste principal, bem como comprimento e largura das folhas e suas partes, são amplamente usados com palmeiras (Child, 1974; Hartley, 1977; Bovi et al., 1992; Clement, 1995; Yuyama, 1997). São medidas de natureza não destrutiva, facilmente obtidas, especialmente nos estádios iniciais de crescimento. Todas apresentam correlações positivas e significativas com a produção de palmito (Clement et al., 1988; Bovi et al., 1988; 1992; 1993a; Szott et al., 1993; Clement, 1995).

Medidas de superfície: área foliar, pela qual se estima teoricamente a superfície fotossinteticamente ativa. Medidas diretas de área foliar são trabalhosas ou mesmo impraticáveis em palmeiras. Estimativas indiretas são obtidas por meio de relações alométricas (Hardon et al., 1969; Clement et al., 1985) ou pela transmitância da radiação a vários ângulos, usando-se equipamento apropriado (Bovi et al., 1997).

Medidas de massa: massa seca é utilizada preferencialmente à massa fresca, pois o teor de água é variável, dependendo das condições de cultivo, colheita e armazenamento pósamostragem. A biomassa pode ser estimada para a planta inteira ou para seus componentes. Em palmeiras, medidas de massa são facilmente obtidas no estádio de mudas, mas apresentam complicações ao longo do ciclo de vida de uma palmeira devido ao porte da planta. Estimativas da biomassa dos componentes da planta, usando-se relações alométricas, são comumente utilizadas para o dendezeiro (Corley et al., 1971). Estimativas indiretas da planta inteira, também aplicando-se relações alométricas, têm sido utilizadas para obter dados de biomassa em pupunheiras cultivadas a campo (Szott et al., 1993; Clement, 1995).

Enquanto medidas lineares e numéricas, tomadas de uma só vez ou repetidas nas mesmas unidades experimentais ao longo do tempo, são eficientes (desde que padronizadas) e práticas para comparar respostas a tratamentos aplicados em experimentos agronômicos e genéticos, medidas de massa e superfície ao longo do tempo vêm sendo usadas para estimar alguns indices fisiológicos clássicos (Radford, 1967; Evans, 1972; Causton \& Venus, 1981). Entre os mais usados estão: índice de área foliar (IAF - o quociente entre a área foliar e o espaçamento da cultura), taxa de crescimento da cultura (TCC - a variação da massa seca ao longo do tempo), taxa de crescimento relativo (TCR - a TCC dividida pela massa seca), taxa de assimilação líquida (TAL - a razão entre TCC e IAF, representando o balanço entre o material produzido pela fotossintese e o perdido pela respiração), e índice de colheita (IC - a razão entre a massa seca da parte economicamente importante pela massa seca total da planta), que representa a eficiência de conversão de produtos sintetizados em 
material de importância econômica. Conhecendo-se a distribuição da matéria seca entre os diversos componentes da planta, podem-se calcular alguns índices que possibilitam compreender a dinâmica do crescimento. Entre os mais usados estão: razão de área foliar (RAF - o quociente entre área foliar e massa seca total da planta), razão de massa foliar (RMF - o quociente entre massa seca das folhas e massa seca total da planta) e área foliar especifica (AFE o quociente entre área foliar e massa seca das folhas). Calcula-se a duração da área foliar (DAF) integrando-se o indice de área foliar com relação ao tempo. Outros indices podem ainda ser usados, dependendo dos objetivos que se tem em mente.

\section{ANÁLISE DA PRODUÇÃO}

A produção de palmito pode ser avaliada de várias formas. A mais comum é pela massa fresca do produto obtido, expressa por planta (g/planta) e por área e por ano ( $\mathrm{kg} / \mathrm{ha} / \mathrm{ano})$. A produção é muito influenciada por deficiência hídrica (Bovi, 1998; Miranda et al., 1998), densidade e adubação (Bovi, 1999; Yuyama, 1997). Alguns resultados tem sido apresentados em número de palmitos e seu peso bruto (e.g., Zamora, 1985). Embora o número de palmitos é importante, o peso bruto não permite uma boa compreensão da produção por planta ou por área, porque inclue uma quantidade muito variável de tecidos fibrosos que serão descartados durante o processamento.
O palmito da pupunheira pode ser comercializado em vários estilos (os mais comuns são: toletes, rodelas, cubinhos ou picado). É recomendável separar a produção em dois componentes: palmito em toletes e demais estilos, visto que o preço do primeiro produto é geralmente o dobro dos demais estilos. Convencionalmente denominam-se os toletes macios de "palmito de primeira", "palmito tipo exportação", "palmito extra", ou simplesmente palmito. Como as embalagens mais comuns para palmito processado são latas ou vidros de $500 \mathrm{~g}$ ( $300 \mathrm{~g}$ peso drenado), estabeleceu-se que cada tolete deve ter $9 \mathrm{~cm}$ de comprimento, e ser completo e sem defeitos físicos ou mecânicos (rachaduras, zonas de maior pressão, bainha externa faltante ou incompleta, etc.) (ANVS, 1999).

Além da massa fresca do produto obtido, separada em palmito de primeira e demais cortes, podemse usar várias outras medidas adicionais, tais como comprimento total aproveitável (número de toletes de primeira multiplicado por $9 \mathrm{~cm}$ ), diâmetro do palmito na base (região do meristema apical), no meio e no ápice (região do final da bainha) e número de folhas internas, contadas na região do meristema apical. Análises para cor, textura e teor de fibras são complementares, sendo utilizadas para diferenciar entre materiais genéticos ou entre tratamentos impostos, tais como adubação, densidade de plantio ou irrigação.

$\mathrm{O}$ número de palmitos colhidos 
por área e por ano dá também uma boa idéia da produção e pode ser usado rotineiramente, especialmente quando a produção é destinada à indústria, onde o controle do peso não pode ser feito tão detalhadamente. Adicionalmente esse número pode ser expresso como a porcentagem do número de plantas no campo (Clement, 1993), sendo afetada pela densidade, adubação, estresse hídrico etc. O número de vidros ou latas de cada estilo produzidos por parcela, pode ser um bom indicador prático da produtividade da parcela, desde que se mencione o peso drenado do produto por lata (Mora Urpí, 1992).

A pupunheira também produz quantidades apreciáveis de estipe tenro, que está sendo vendido no mercado em rodelas, cubos, esferas e picado, freqüentemente misturado com palmito tratado da mesma forma. Deu-se a esse componente da produção o nome de "coração" (Ferreira et al., 1982), considerado inadequado por ser idêntico ao nome de palmito no exterior (heart-of-palm, coeur du palmier, coração de palmeira etc.). Esse componente da produção, aqui denominado estipe tenro ou residuo basal, deve ser expresso como o palmito (g/planta ou $\mathrm{kg} / \mathrm{ha} / \mathrm{ano}$ ). Resíduo apical ou folha tenra é composto por ráquis e folíolos tenros (tecido foliar não envolto pela bainha, como no caso do palmito), obtidos após o corte do último tolete de palmito de primeira. Esse componente deve ser expresso também como o palmito ( $\mathrm{g} /$ planta ou $\mathrm{kg} / \mathrm{ha} / \mathrm{ano}$ ). $\mathrm{Na}$ maior parte das indústrias brasileiras, o resíduo basal e o apical são processados juntos, no estilo picado, dando origem ao chamado palmito de segunda. Estilos mais elaborados, tais como o "hóstia" e o "bolinha" têm sido usados para valorizar o produto obtido do resíduo basal.

\section{DETERMINAÇÃO DE MEDIDAS DE SUPERFÍCIE E MASSA}

Formas de estimar a área foliar e biomassa, tanto para a planta inteira como para seus componentes, foram desenvolvidas para a pupunheira e são apresentadas a seguir. É importante frisar que essas relações alométricas precisam ser validadas para cada germoplasma e ambiente (latitude, altitude, solo, adubação, irrigação, densidade), pois área foliar e biomas: são parâmetros altamente plásticos, : 'c seja, possuem baixa herdabilidade (Clement, 1995).

Área foliar: Clement \& Mora Urpí (1983) forneceram uma descrição detalhada da folha dessa palmeira e das variações encontradas em suas dimensões e componentes. A folha é pinada, mas os folíolos estão dispostos em grupos ao longo da ráquis, sendo o primeiro folíolo de cada grupo aproximadamente perpendicular à ráquis, estando os folíolos subsequentes dispostos cada vez mais na posição horizontal. Essa disposição dá à folha da pupunheira uma aparência desalinhada (em contraste com o coqueiro, onde todos os foliolos estão num único plano) e teoricamente permite maior eficiência na absorção de luz. O comprimento dos foliolos 
varia de forma imprevisível ao longo da ráquis, dificultando a padronização dos mesmos para estimativas de área foliar. As primeiras folhas juvenis da pupunheira são bifidas, formadas pela fusão dos foliolos.

Clement et al. (1985), usando pupunheiras adultas de germoplasma costarriquenho, adaptaram metodologia para estimar a área foliar de folhas individuais desenvolvida para o dendezeiro por Hardon et al. (1969). A modificação principal estava na seleção de foliolos. Contaram-se os foliolos e selecionou-se o primeiro folíolo de cada um dos seguintes grupos: 6, 10 e 14 no lado direito; 8 , 12 e 16 no lado esquerdo da ráquis. Mediu-se o comprimento e a largura máxima de cada um dos seis folíolos, usando-se a média dos dados para a estimativa da área foliar, conforme fórmula expressa abaixo:

$$
\begin{aligned}
& \text { área foliar }\left(\mathrm{m}^{2}\right)=0,583 * \\
& (\mathrm{c} * \operatorname{lm}) * \mathrm{n},
\end{aligned}
$$

onde ' $c$ ' é o comprimento médio dos foliolos (em m), 'Im' é a largura máxima média dos folíolos (em $\mathrm{m}$ ) e 'n' é o número total de folíolos. A constante $(0,583)$ ajusta a forma retangular $(\mathrm{c} * 1 \mathrm{~m})$ para o formato da folha. Essa função estima a área foliar com um erro de aproximadamente $5 \%$. A validação dessa equação foi feita por Martel \& Clement (1986/87) em populações de pupunheira das raças Puıumayo, Solimões e Pará, com erros aceitáveis. Clement (1986) sugeriu que o uso apenas dos foliolos de um lado da ráquis, multiplicado por dois, reduziria o trabalho sem diminuir muito a precisão da estimativa. Adotando esse procedimento em plantas jovens do germoplasma Putumayo, Clement (1995) fez um pequeno ajuste no fator de correção de forma $(0,535)$ :

área foliar $\left(\mathrm{m}^{2}\right)=0,535 *$
$(\mathrm{c} * \mathrm{~m}) * \mathrm{n}$
É importante frisar que a equação de 1985 foi desenvolvida para folhas de pupunheiras adultas, enquanto a de 1995 foi desenvolvida para folhas pinadas de plantas imaturas, como as presentes em experimentos para palmito.

Uma equação para estimar a área foliar total da planta foi desenvolvida por Clement (1995) para germoplasma Putumayo, considerando desde o transplante ao campo até $120 \mathrm{~cm}$ de altura (idade de corte). Para este período inteiro a melhor relação alométrica foi:

área foliar total $\left(\mathrm{m}^{2}\right)=-0,852+$ $6,49 * a$,

onde 'a' é a altura da planta (do solo até a forquilha entre a folha guia, ou flecha, e a folha mais nova expandida). Embora essa equação tenha um $\mathrm{R}^{2}=0,95(\mathrm{n}=27$, a mín $=$ $0,1 \mathrm{~m}$, a $\operatorname{máx}=1,7 \mathrm{~m})$, ela ocasionalmente produz estimativas negativas em plantas muito pequenas, 
sugerindo que deve haver relações alométricas distintas para as duas fases ontogenéticas (fase de folha bifida e fase de folha pinada):

área foliar total para a fase bífida $\left(m^{2}\right)=0,157 * a^{1,61} * \mathrm{nf}^{1,85}$

$\mathrm{e}$

área foliar total para a fase pinada $\left(m^{2}\right)=-1,07+6,69 * a$,

onde 'a' é a altura da planta, "nf' é o número de folhas e a função exponencial foi derivada de transformações logarítmicas na base natural. A primeira equação (bifida) tem um $\mathrm{R}^{2}=0,95(\mathrm{n}=9$, a min $=0,1$ $\mathrm{m}$, a máx $=0,45 \mathrm{~m}$ ) e a segunda (pinada) tem um $\mathrm{R}^{2}=0,92(\mathrm{n}=18$, a $\min =0,46 \mathrm{~m}$, a máx $=1,7 \mathrm{~m}$ ).

Biomassa: Clement et al. (1990) adaptaram a equação desenvolvida por Corley et al. (1971) para o dendezeiro visando estimar a biomassa foliar para pupunheiras de três raças distintas (Pará, Pampa Hermosa, Putumayo), usando transformações logarítmicas (base 10):

$\log _{10}$ biomassa foliar $(\mathrm{g})=0,97$ * $\log _{10}(1 *$ em $)$

onde 'l' é a largura da ráquis foliar $(\mathrm{mm})$ na altura da inserção do primeiro folíolo, 'em' é a espessura máxima da ráquis $(\mathrm{mm})$ nesse mesmo ponto e 0,97 é o coeficiente de correção para a estimativa da biomassa foliar. Essa relação alométrica permite estimar a biomassa foliar com erros menores que $5 \%$. Uma função mais precisa foi obtida posteriormente por Clement (1995) usando transformação logarítmica na base natural:

biomassa foliar $(g)=-193+22,9$ * em,

onde 'em' é a espessura máxima $(\mathrm{mm})$ da ráquis foliar no ponto de inserção do primeiro folíolo. Essa equação é adequada para folhas pinadas de plantas jovens, não tendo sido validada em plantas adultas.

Quando o palmito é extraido antes do aparecimento dos primeiros anéis do estipe (corte comum na Costa Rica, mas não no Brasil, devido a demanda do mercado brasileiro por palmito de diâmetro médio maior $(2,5$ a 3,5 cm); refira-se a Mora Urpí et al., 1997, para caracterização do produto destinado a diferentes mercados), a biomassa do estipe pode ser desconsiderada, de tal forma que a massa seca, a taxa de crescimento da cultura (TCC) ou demais indices fisiológicos podem ser calculados usando-se apenas dados das folhas. Para os diâmetros de palmito preferidos na região Sudeste brasileira, a biomassa do estipe não pode ser desconsiderada e novas equações devem ser desenvolvidas para a estimativa correta.

Szott et al. (1993) examinaram relações alométricas em pupunheiras adultas e jovens da população de Yurimaguas, Peru (raça Pampa Hermosa), e desenvolveram equações para estimar biomassa usando apenas a altura e a combinação de altura e número de folhas: 
Como ocorre com a área foliar

biomassa total $(\mathrm{kg})=0,735 * \mathrm{a}^{2}$ e

biomassa total $(\mathrm{kg})=0,549 * \mathrm{a}^{2}$ $+0,077 * \mathrm{nf}^{2}$,

onde 'a' é a altura da planta (m) medida do solo até a forquilha entre a guia e a folha mais nova expandida e 'nf' é o número de folhas verdes expandidas. A primeira equação tem um $\mathrm{R}^{2}=0,95$ e a segunda um $\mathrm{R}^{2}=$ 0,96 , sugerindo que o número de folhas aumenta muito pouco a precisão da estimativa. Ambas equações superestimam a biomassa total de plantas jovens. Devido a isso, esses autores desenvolveram relações alométricas para plantas mais jovens (altura $<4,2 \mathrm{~m}$ ), desta vez usando número de folhas e diâmetro do estipe:

biomassa total $(\mathrm{kg})=0,032 * \mathrm{~d}^{2}$ e

biomassa total $(\mathrm{kg})=-0,24+$ $0,024 * \mathrm{nf}^{2}+0,020 * \mathrm{~d}^{2}$,

onde ' $\mathrm{d}$ ' é o diâmetro do estipe (cm) a $0,65 \mathrm{~m}$ do solo e ' $n f$ ' é o número de folhas. A primeira equação tem um $\mathrm{R}^{2}=0,89$ e a segunda um $\mathrm{R}^{2}$ $=0,95$. A razão provável pela qual $\mathrm{d}^{2}$ é menos eficiente para estimar biomassa se deve a que a $0,65 \mathrm{~m}$ de altura o diâmetro se refere a diferentes componentes da planta e não só a estipe, isto é, em plantas jovens 0,65 m pode ser o diâmetro da coroa e é composto por pecíolos foliares de diferentes espessuras, enquanto em plantas adultas refere-se ao diâmetro do estipe propriamente dito. total, as relações alométricas usadas para estimar biomassa total provaramse inadequadas para plantas muito jovens, subestimando os valores, com ocorrência ocasional de números negativos. Consequentemente, Clement (1995) desenvolveu relações alométricas específicas para cada fase de crescimento:

biomassa total (fase bifida) $(\mathrm{kg})$ $=0,027 * \mathrm{a}^{1,93} * \mathrm{nf}^{2,05}$

$\mathrm{e}$

biomassa total (fase pinada) $(\mathrm{kg})=-0,557+1,92 * \mathrm{a}$

onde 'a' e 'nf' são como antes. Ambas equações tem um $\mathrm{R}^{2}=0,97$ (para n, a mín e máx, veja equações de área foliar acima). Nenhuma das duas relações alométricas foi validada para outras localidades e germoplasma, e ambas foram desenvolvidas usando-se amostras pequenas. Pesquisas estão em andamento para validá-las para germoplasma de Pampa Hermosa, em condições de alto e baixo uso de insumos num latossolo amarelo na Amazônia Central.

\section{PADRONIZAÇÃO DE MEDIDAS}

É extremamente importante que se padronize as medidas a serem tomadas em experimentos com pupunheiras, para permitir comparação entre experimentos. Além da padronização, é essencial que cada relatório experimental inclua todas as informações sobre o germoplasma e o ambiente (latitude, altitude, solo, 
adubação, irrigação, densidade de plantio), pois na sua ausência, a padronização perde parte de seu valor. Para facilitar essa padronização, sugerem-se os seguintes critérios:

\section{Crescimento}

a. Altura da planta (cm ou m) É medida do solo até o ponto entre a flecha e a folha mais nova (a forquilha formada entre a folha flecha, que é numerada de 0 , e a primeira folha expandida, que é numerada de +1 ). A altura da planta está altamente correlacionada com a biomassa e a área foliar (Clement, 1995), assim como com a produção de palmito (Bovi et al., 1992; 1993a; Moreira \& Arkcoll, 1988), sendo uma das características mais facilmente mensuráveis em experimentos visando a produção de palmito.

b. Número de folhas - É o número de folhas verdes completamente expandidas da haste principal. Ignorar folhas amarelas ou mortas, visto que elas não são fotossinteticamente ativas. O número de folhas verdes tende a decrescer com a densidade populacional, o déficit hídrico e a deficiência nutricional e é útil em combinação com outros caracteres.

c. Número de perfilhos da touceira - Está diretamente relacionado com a duração econômica do cultivo e com a capacidade de regeneração da touceira após a colheita. Deve ser medida logo antes do primeiro corte na touceira.

d. Diâmetro da base $(\mathrm{cm})$ - Em plantas muito jovens é medido no coleto e a $10 \mathrm{~cm}$ acima da superfície do solo. Em plantas maiores (acima de $120 \mathrm{~cm}$ ) o diâmetro é mais facilmente medido a $50 \mathrm{~cm}$ de altura, especialmente quando existe farto perfilhamento na base. $\mathrm{O}$ diâmetro da base está altamente correlacionado com o peso de palmito (Bovi et al., 1992; 1993a) e a biomassa total, mas é mais dificil de ser mensurado com precisão devido a presença de perfilhos e a ocorrência de espinhos em alguns materiais. Portanto, o diâmetro é uma medida opcional.

e. Área foliar $\left(\mathrm{m}^{2}\right)$ - Para folhas individuais, esta deveria ser estimada na terceira folha expandida na coroa da planta, usando o método de Clement et al. (1985) ou Clement (1995), devidamente validado para o experimento em questão. Como o palmito é cortado de plantas jovens, cada folha mais nova na coroa será maior que a mais velha, se as plantas são adequadamente nutridas. Uma planta de tamanho apropriado para o corte raramente tem mais de 6-10 folhas na densidade comercial (5000 plantas/ha), de forma que medir a terceira permite uma estimativa razoável. Se houver necessidade de maior precisão, medem-se a segunda, a quarta, a sexta e a oitava folhas. A área foliar total pode ser obtida multiplicando-se o valor mensurado pelo número de folhas, ou estimada com a equação proposta por Clement (1995), devidamente validada para o experimento em questão. A área foliar é opcional, exceto quando se pretende estimar índices fisiológicos.

f. Biomassa foliar $(\mathrm{g})$ - Da 
mesma forma como para a área foliar, esta deveria ser estimada na terceira folha, com a metodologia proposta por Clement et al. (1990) ou Clement (1995), devidamente validada para o experimento em questão. A biomassa foliar total pode ser obtida multiplicando-se a biomassa da folha pelo número de folhas, ou estimada pela equação proposta por Clement (1995), sempre validada para o experimento em estudo, se as plantas não possuem estipes. Se possuem, revalidar a equação com base em plantas maiores, que incluem o estipe. Caso haja necessidade de dados sobre a touceria, por exemplo para TCC e TCR em condições de campo, usar o somatório da estimativa da biomassa de cada perfilho. A biomassa foliar é opcional, exceto quando se pretende estimar indices físiológicos.

\section{Produção}

g. Número de palmitos - Este é o número de palmitos extraídos de uma touceira ou de sua unidade experimental durante um ano. Pode ser usado para calcular a porcentagem de corte $\left(\mathrm{n}^{\circ}\right.$ palmitos $/ \mathrm{n}^{\circ}$ plantas na unidade).

h. Peso do palmito $(\mathrm{g})$ - deve ser exclusivamente o peso do palmito tipo exportação. É o peso fresco dos toletes - de um a cinco (raramente mais) extraídos imediatamente acima do meristema. Cada tolete deve ter $9 \mathrm{~cm}$ de comprimento. Determina-se a característica "qualidade de exportação" por meio da pressão exercida por faca bem afiada sobre a seção mais grossa do tolete. A faca não encontrará resistência à penetração se aquela seção do palmito contiver apenas fibras macias.

i. Comprimento do palmito $(\mathrm{cm})$ - Este é o comprimento do palmito de exportação e é um múltiplo de 9 , pois é simplesmente o número de toletes inteiros multiplicado pelo tamanho padrão do tolete $(9 \mathrm{~cm})$.

j. Peso do estipe tenro (residuo basal) (g) - Este componente é a porção do estipe imediatamente abaixo do meristema, que é bastante tenro para ser comido in natura. $\mathrm{O}$ residuo basal é opcional.

k. Peso da folha tenra (resíduo apical) (g) - Este é composto por partes das folhas (geralmente ráquis e folíolos) acima do último tolete completo de palmito, suficientemente tenras para serem comidas in natura. O resíduo apical é opcional.

1. Diâmetro do palmito $(\mathrm{mm})$ Este é o diâmetro médio dos $\mathrm{n}$ toletes de palmito de exportação, cada tolete medido no seu ponto central.

\section{Validação}

A validação é um processo simples, mas precisa ser planejada $a$ priori. O ideal é que parcelas extras sejam alocadas em cada tratamento dentro de um experimento para prover amostras (periódicas, se necessário) para validação das equações. Para executar a validação, simplesmente escolher 20 plantas (ou folhas individuais), efetuar todas as medidas lineares sugeridas acima, separar todas as folhas da haste principal, medir a 
área foliar (a tarefa mais trabalhosa na ausência de equipamento, mas possível com papel milimetrado), pesar todos os componentes individualmente (massa fresca), secar tudo a $60^{\circ} \mathrm{C}$ até peso constante, pesar novamente (massa seca) e refazer as regressões em que as equações são baseadas (solicite a ajuda de um estatístico se for necessário). As novas equações serão similares às apresentadas acima e serão validadas para cada caso.

\section{CONCLUSÕES}

Esta lista de medidas para avaliação é relativamente curta e os dados individuais são relativamente fáceis de serem coletados. Algumas medidas são opcionais, outras são baseadas em equações alométricas que precisam ser validadas.

Os parâmetros de crescimento e produção, além de alguns índices físiológicos estimados por meio deste pequeno conjunto padronizado de medidas, permitirão melhor compreensão de como a pupunheira reage aos tratamentos aplicados, possibilitando ainda a comparação direta entre diferentes genótipos e ambientes, bem como a uniformização da terminologia usada no relato de resultados de pesquisa com essa palmeira.

\section{AGRADECIMENTOS}

$\mathrm{O}$ primeiro autor agradece $\mathrm{o}$ apoio financeiro de PRODETAB, via o projeto 'Manejo racional de água na pupunha para produção de palmito no submédio São Francisco e no noroeste Paulista', coordenado pelo M.Sc. José Egídio Flori, Embrapa Semi-Árido, e do INPA, via o projeto 'Sistemas de produção rural na Amazônia Brasileira', coordenado pelo Dr. Kaoru Yuyama.

\section{Bibliografia citada}

ANVS. 1999. Resolução № 362: Regulamento técnico referente a padrão de identidade $\mathrm{e}$ qualidade para palmito em conserva. Diário Oficial da União, 137(146-E) de 02/08/99.

Bovi, M.L.A. 1998. Palmito pupunha: informações básicas para cultivo. Boletin Técnico 173, Instituto Agronômico, Campinas. 50p.

Bovi, M.L.A. 1999. Manejo agronômico da pupunheira: conhecimentos atuais e necessidades. In: Anais do $I^{\circ}$ Seminário do Agronegócio de Palmito de Pupunha na Amazônia. (Embrapa-CPAF/RO, Documentos 41) Embrapa Rondonia, Porto Velho, p.44-56.

Bovi, M.L.A.; Godoy Júnior, G.; Saes, L.A. 1988. Pesquisas com os gêneros Euterpe e Bactris no Instituto Agronômico de Campinas. In: Anais do $l^{\circ}$ Encontro Nacional de Pesquisadores em Palmito, (EMBRAPA-CNPF, Documentos, 19). EMBRAPA-CNPF, Curitiba, PR. pp.1-43.

Bovi, M.L.A.; Saes, L.A.; Godoy Júnior, G. 1992. Correlações fenotípicas entre caracteres não destrutíveis e palmito em pupunheiras. Turrialba, 42(3):382-390.

Bovi, M.L.A.; Godoy Júnior, G.; Camargo, S.B.; Spiering, S.H. 1993a. Caracteres indiretos na seleção de pupunheiras inermes (Bactris gasipaes H.B.K.) para palmito. In: Mora Urpí, J.; Szott, L.T.; Murillo, M.; Patiño, V.M. (Eds.). Anais do $4^{\circ}$ Congreso Internacional sobre Biologia, Agronomia e Industrialización del Pijuayo, Iquitos, 1991. Univ. Costa Rica, San José. pp.163-176.

Bovi, M.L.A.; Godoy Júnior, G.; Camargo, S.B.; Spiering, S.H. 1993b. Seleção precoce 
em pupunheiras (Bactris gasipaes H.B.K.) para produção de palmito. In: Mora Urpi, J.; Szott, L.T.; Murillo, M.; Patiño, V.M. (Eds.). Anais do $4^{\circ}$ Congreso Internacional sobre Biologia, Agronomia e Industrialización del Pijuayo, Iquitos, 1991. Univ. Costa Rica, San José. pp.177-185.

Bovi, M.L.A.; Tucci, M.L.S.; Machado, E.C.; Spiering, S.H.; Hass, F. 1997. Relação entre indice de área foliar e produtividade em pupunheira. In: Resumos do VI Congresso Brasileiro de Fisiologia Vegetal, Belém, 1997. Soc. Bras. Fisiologia Vegetal, Belém. p.182.

Bovi, M.L.A.; Basso, L.C.; Tucci, M.L.S. 1998. Avalicação da atividade in vitro da fosfatase ácida e do crescimento de progênies de pupunheira cultivadas em duas doses de nitrogênio e fósforo, Revista Brasileira de Ciencia do Solo, 22:427-434.

Camacho, E.; Soria, J. 1970. Palmito de pejibaye. In: Proceedings of the American Society for Horticultural Science, Caribbean Region, 14:122-132.

Causton, D.R.; Venus, J.C. 1981. The biometry of plant growth. Edward Arnold, London. $307 \mathrm{p}$.

Child, R. 1974. Coconuts (Cocos nucifera L.), 2nd ed. Longman, London. 335p.

Clement, C.R. 1986a. Bactris gasipaes - Lista minima de descriptores para el banco de germoplasma. CATIE/GTZ, Turrialba. $15 \mathrm{p}$.

Clement, C.R. 1986b. Descriptores minimos para el pejibaye (Bactris gasipaes H.B.K.) y sus implicaciones filogenéticas. M.Sc. thesis. Universidad de Costa Rica, San José. $216 \mathrm{p}$.

Clement, C.R. 1993. Pejibaye palmito at high planting density: results and suggestions. In: Mora Urpí, J.; Szott, L.T.; Murillo, M.; Patiño, V.M. (Eds.). Anais do $4^{\circ}$ Congreso Internacional sobre Biologia, Agronomia e Industrialización del Pijuayo, Iquitos, 1991. Univ. Costa Rica, San José. pp.237253.

Clement, C.R. 1995. Growth and genetic analysis of pejibaye (Bactris gasipaes
Kunth, Palmae) in Hawaii. PhD dissertation. University of Hawaii at Manoa, Honolulu, HI. $221 \mathrm{p}$.

Clement, C.R.; Mora Urpí, J. 1983. Leaf morphology of the pejibaye palm (Bactris gasipaes H.B.K.). Revista de Biologia Tropical, 31(1):103-112.

Clement, C.R.; Mora Urpi, J.; Costa, S.S. 1985. Estimación del area foliar del pejibaye (Bactris gasipaes H.B.K.). Revista de Biologia Tropical, 33(2):99-105.

Clement, C.R.; Chávez Flores, W.B.; Moreira Gomes, J.B. 1988, Considerações sobre a pupunha (Bactris gasipaes H.B.K.) como produtora de palmito. In: Anais do $1^{\circ}$ Encontro Nacional de Pesquisadores em Palmito, (EMBRAPA-CNPF, Documentos, 19). EMBRAPA-CNPF, Curitiba, PR. pp.225-247.

Clement, C.R.; Campos, J.K.P.; Plácido Neto, J.J. 1990. Estimación de la biomassa de la hoja del pejibaye (Bactris gasipaes H.B.K.). Revista de Biologia Tropical, 38(2B):395-400.

Corley, R.H.V.; Hardon, J.J.; Tan, G.Y. 1971. Analysis of growth of the oil palm (Elaeis guineensis Jacq.). I. Estimation of growth parameters and application in breeding. Euphytica, 20:307-315.

Evans, G.C. 1972. The quantitative analysis of plant growth. Blackwell Scientific, Oxford. 734p.

Ferreira, V.L.P.; Miya, E.E.; Shirose, 1.; Aranha, C.; Silva, E.A.M.; Highlands, M.E. 1976. Comparação físico-químicosensorial do palmito de três espécies de palmeiras. Coletânea do Instituto de Tecnologia de Alimentos, 7(2):389-416.

Ferreira, V.L.P.; Bovi, M.L.A.; Angelucci, E.; Figueiredo, I.B.; Yokomizo, Y.; Sales, A.M. 1982. Estudo dos palmitos das palmeiras e do híbrido de Euterpe edulis Mart. (juçara) e Euterpe oleracea Mart. (açai). II. Avaliações físicas e quimicas. Coletânea do Instituto de Tecnologia de Alimentos, 12:243-254.

Germek, E.B. 1978. Cultura experimental da pupunha no Estado de São Paulo. $O$ Agronômico, 29:96-103. 
Hardon, J.J.; Williams, C.N.; Watson, I. 1969. Leaf area and yield of the oil palm in Malaysia. Experimental Agriculture, 5:25-32.

Hartley, C.W.S. 1977. The oil palm (Elaeis guineensis Jacq.), 2nd ed. Longman, London. 806p.

Martel, J.H.I.; Clement, C.R. 1986/87. Comparação preliminar da área foliar de três acessos de pupunha (Bactris gasipaes H.B.K., Palmae) oriundos de três populações distintas da Amazônia Ocidental. Acta Amazonica, 16/17:13-18.

Miranda, R.M.; Lima, H.C.; Martins, G.C. 1998. Estudo comparativo entre número de perfilhos no cultivo da pupunheira sem espinhos (Bactris gasipaes Kunth) para produção de palmito. Boletim de Pesquisa $\mathrm{n}^{9}$ 5, Embrapa Amazônia Ocidental, Manaus. 25p.

Mora Urpí, J. 1992. Bases para evaluar comercialmente futuras inovaciones en el cultivo de pejibaye para palmito. Boletin Pejibaye (Guilielma), 4(1):18-19.

Mora Urpi, J.; Weber, J.C.; Clement, C.R. 1997. Peach palm. Bactris gasipaes Kunth. Promoting the conservation and use of underutilized and neglected crops. 20. Institute for Plant Genetics and Crop Plant Research - IPK, Gatersleben / International Plant Genetic Resources Institute - IPGRI, Rome. 83p.

Moreira Gomes, J.B.; Arkcoll, D.B. 1988. Estudos iniciais sobre a produção de palmito de pupunha. In: Anais do $I^{\circ}$ Encontro Nacional de Pesquisadores em Palmito,

(EMBRAPA-CNPF, Documentos, 19). EMBRAPA-CNPF, Curitiba. pp.271-278.
Moreira Gomes, J.B.; Menezes, J.M.T.; Viana Filho, P. 1988. Efeito de níveis de adubação e espaçamento na produção de palmito de pupunheira (Bactris gasipaes H.B.K.) em solo de baixa fertilidade na região de Ouro Preto D'Oeste, Rondônia. In: Anais do $1^{\circ}$ Encontro Nacional de Pesquisadores em Palmito, (EMBRAPA-CNPF, Documentos, 19). EMBRAPA-CNPF, Curitiba. pp. 261-266.

Radford, P.J. 1967. Growth analysis formulae - their use and abuse. Crop Science, 7:171-175.

Ramos, A.R.; Folegatti, M.V.; Bovi, M.L.A. 1999. Desenvolvimento vegetativo da pupunheira (Bactris gasipaes Kunth) irrigada por gotejamento em função de diferentes níveis de depleção de água no solo. In: Anais do $28^{\circ}$ Congresso Brasileiro de Engenharia Agricola (CDROM). Soc. Bras. Engenharia Agrícola, Pelotas. $8 \mathrm{p}$.

Szott, L.T.; Arévolo, L.; Pérez, J. 1993. Allometric relationships in pijuayo (Bactris gasipaes H.B.K.). In: Mora Urpi, J.; Szott, L.T.; Murillo, M.; Patiño, V.M. (Eds.). Anais do $4^{\circ}$ Congreso Internacional sobre Biologia, Agronomia e Industrialización del Pijuayo, Iquitos, 1991. Univ. Costa Rica, San José. pp.91-114.

Yuyama, K. 1997. Sistemas de cultivo para produção de palmito da pupunheira. Horticultura Brasileira, 15 (Suplemento): 191-198.

Zamora, C. 1985. Densidades de siembra de pejibaye para palmito con tallo simple. In: Sexto Informe de Labores de Diversificación Agrícola 1983-1984. Associación Bananera Nacional, San José, Costa Rica. pp.75-78. 